\section{Nicotine replacement therapy: evidence from observational studies versus clinical trials}

To THE EDITOR: George, ${ }^{1}$ who has received a research grant from Pfizer on smoking cessation, makes the manifestly incorrect statement that "there is no evidence for the effectiveness of cold turkey cessation, especially in moderate to heavy smokers". In fact, it has always been the case that the most common method used by ex-smokers in their final successful attempt to quit is cold turkey. ${ }^{2}$

Those promoting pharmacological approaches to cessation typically base their recommendations on results from clinical trials. But clinical trial results do not reflect "real-world" results; people using pharmaceutical aids tend to have lower smoking cessation rates than people who quit unaided, because of indication bias (in which smokers with a high nicotine dependency and the worst cessation prognosis self-select to use pharmaceutical aids). ${ }^{3}$

A meta-analysis of nicotine replacement therapy (NRT) trials concluded that "... the true overall impact of NRT ... is similarly modest and represents success for only about $7 \%$ of all those treated in these trials". ${ }^{4}$

Smoking cessation trials exclude large numbers of smokers, have participant "blindness" integrity problems (those on placebo often accurately guess that they have not been allocated to the treatment arm), and those in the treatment arm, by virtue of knowing that they are being studied, have higher rates of treatment completion than smokers in the community because of the Hawthorne effect.

Before the introduction of NRT over 20 years ago, the American Cancer Society estimated that "over $90 \%$ of the estimated 37 million people who have stopped smoking in this country since the Surgeon General's first report linking smoking to cancer have done so unaided" ${ }^{5}$ Recent reviews have concluded that the advent of smoking cessation pharmacotherapies has not translated into increased rates of cessation in the population. ${ }^{6}$

\section{Simon Chapman Professor}

School of Public Health, University of Sydney, Sydney, NSW.

\section{simon.chapman@sydney.edu.au}

Competing interests: I have a grant from the National Health and Medical Research Council for research on the natural history of unassisted smoking cessation. I am a board member of Action on Smoking and Health, Australia.

\section{doi: 10.5694/mjal2.10590}

1 George J. Nicotine replacement therapy: evidence from observational studies versus clinical trials. Med J Aust 2012; 196: 383.

2 Chapman S, Mackenzie R. The global research neglect of unassisted smoking cessation: causes and consequences. PLoS Medicine 2010; 7: e1000216. doi: 10.1371/journal.pmed.1000216.

3 Shiffman S, Di Marino ME, Sweeney CT. Characteristics of selectors of nicotine replacement therapy. Tob Control 2005; 14: 346-355.

4 Etter JF, Stapleton JA. Nicotine replacement therapy for long-term smoking cessation: a metaanalysis. Tob Control 2006; 15: 280-285.

5 American Cancer Society. Cancer facts and figures (1986). Atlanta: ACS, 1986.

6 Pierce JP, Cummins SE, White MM, et al. Quitlines and nicotine replacement for smoking cessation: do we need to change policy? Ann Rev Pub Health 2012;33:341-356.
IN REPLY: The response of Chapman to my article is not surprising, given his involvement in the Alpert article. ${ }^{1}$ The recommendations of Alpert and colleagues have already been criticised internationally, and debate on the effectiveness of pharmacological smoking cessation therapies is not new. Meta-analyses have shown 50\% to $70 \%$ greater quit rates for nicotine replacement therapy (NRT) compared with placebo or in controls. ${ }^{2,3}$ Advocates of cold turkey cessation question the effectiveness of NRT in the "real world", using data from population studies. ${ }^{1,4,5}$

Multiple attempts are often necessary before a smoker can successfully quit. Smokers with a history of failure to quit without support may find behavioural counselling and pharmacological aids to be useful in their quit attempts and in achieving long-term success.

The National Health and Medical Research Council recommendations for developers of guidelines place randomised controlled trials well above observational studies in the study validity hierarchy. The submission to list nicotine patches on the Pharmaceutical Benefits Scheme was made by a consortium of independent public health organisations. Advocates of unassisted smoking cessation should provide stronger evidence to convince policymakers and practitioners.

Johnson George Senior Lecturer

Centre for Medicine Use and Safety, Monash University, Parkville, VIC.

Advocates of unassisted smoking cessation should provide stronger evidence

\section{Johnson.George@monash.edu}

Competing interests: I am an investigator in the Give Up For Good clinical trial, evaluating a multidisciplinary smoking intervention initiated during hospital stay, funded by the Australian Research Council and an investigator-initiated research grant from Pfizer.

doi: 10.5694/mjal2.10653

1 Alpert HR, Connolly GN, Biener L. A prospective cohort study challenging the effectiveness of population-based medical intervention for smoking cessation. Tob Control 2012. doi: 10.1136/ tobaccocontrol-2011-050129.

2 Stead LF, Perera R, Bullen C, et al. Nicotine replacement therapy for smoking cessation. Cochrane Database Syst Rev 2008; (1): CD000146.

3 Moore D, Aveyard P, Connock M, et al. Effectiveness and safety of nicotine replacement therapy assisted reduction to stop smoking: systematic review and meta-analysis. BMJ 2009; 338: b1024.

4 Pierce JP, Gilpin EA. Impact of over-the-counter sales on effectiveness of pharmaceutical aids for smoking cessation. JAMA 2002; 288: 1260-1264.

5 Alberg AJ, Patnaik JL, May JW, et al. Nicotine replacement therapy use among a cohort of smokers. J Addict Dis 2005; 24: 101-113. 